\title{
Formation of professional skills the system of driver training
}

\author{
Evgeny Ageev ${ }^{1}$, Alexander Novikov ${ }^{2}$ and Evgeny Vinogradov ${ }^{1 *}$ \\ ${ }^{1}$ FGBOU VO South-West state University, 305040, Kursk, Russia \\ ${ }^{2}$ FGBOU VO Orel State University named after I. S. Turgenev, 302026, Orel, Russia
}

\begin{abstract}
The article presents a structural diagram of the driver's activity associated with driving a car, identifies the factors that affect the reliability of the driver's actions, contributing to the prediction of road accidents in road transport, and addresses the issues of indicators of actions performed when driving a car in the system of professional training of drivers. The article presents the methodology of training on the training complex, which allows you to determine the indicator of professional skill of safe driving, focused on creating a structure of the main elements that affect the quality of safe behavior on the road and the reliability of the actions performed associated with the preparation for independent work.
\end{abstract}

\section{Introduction}

The driver, as the operator of the «Driver-Car-Road-Environment» system, receives the main information from the road section on which he is driving, while the change of events forms a response to a variety of road situations [1]. Guided by the incoming information, the driver chooses the best way to respond, performs maneuvers, and monitors the development of road situations [2-5].

At the same time, the reliability of the actions performed is determined by the professional qualities of the driver's activity, and depends on the skills (qualities) that the candidate has as a result of training in the training center (sensation, perception, attention, thinking, memory, emotional component). Professional reliability is achieved through training in the course of training and subsequent professional activities $[6,7]$.

The reliability indicator depends on the personal qualities of the student enrolled in the training course, the level of qualification of the teaching staff, the ability to correctly choose the methods and means of training, taking into account the individual approach [8]. The general scheme of reliability of the formed skills of driving activity related to driving a vehicle is presented in figure 1 .

Consider the main activities of the driver to drive a car on the roads. Driving the car is carried out due to the impact on the controls (steering wheel, throttle drive, clutch and brake pedals, gear lever, turn indicator toggle switch, etc.). From the point of view of the formation of professional training of the candidate for drivers, the impact skills should be

\footnotetext{
* Corresponding author: ganek09@,rambler.ru
} 
brought to automatism excluding eye contact. The formation of these skills is carried out at the stage of simulator training with subsequent attachment to the car.

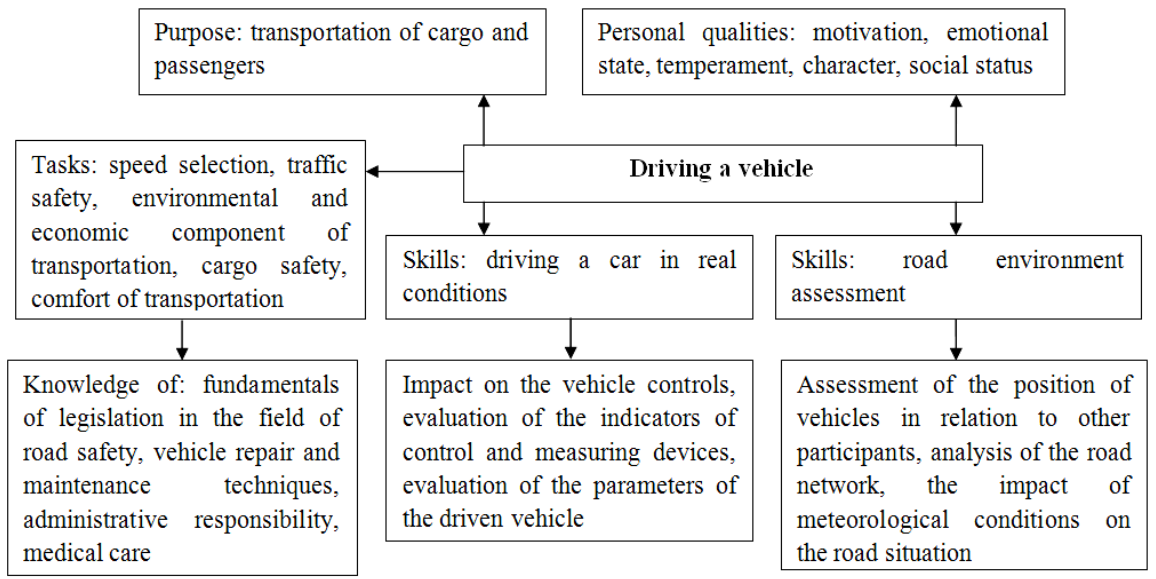

Fig. 1. Block diagram of the driver's driving activity

When driving a vehicle, the driver must have the skills to read the indicators from the instrument panel. This is necessary for analyzing the technical condition and operating mode of the engine, units and systems of the car. For the correct assessment of a candidate driver in the course of training, it is necessary to acquire knowledge about the requirements for the device of the car, the assessment of the readiness of the skill is carried out according to the results of an oral survey.

The formation of the skill of driving a car associated with the choice of speed, performing maneuvers, analyzing dimensions contributes to a comprehensive assessment of the development of the road traffic situation (RTS). The assessment of the skill associated with the technique of driving a vehicle is carried out by inference, based on the analysis of visual sensations of changing events occurring on the road. At the same time, the driver in the process of control forms a system of motor, sensory, and mental skills and abilities necessary for professional activity.

The driver's assessment of his position in the car is carried out through feelings of discomfort or fatigue, the appearance of errors, and the performance of additional maneuvers. The need to assess the placement in the car contributes to the creation of a level of comfort, which has a significant impact on performance and reduces fatigue, including the microclimate affects the perception of the surrounding reality.

The assessment of visibility from the driver's seat is based on the assessment of the border and angle of view, the operational condition of the front, rear and side windows, rear-view mirrors of the car.

The driver's sense of the dimensions of the driven car is an important skill necessary in any traffic accident, especially when driving in traffic, when overtaking, detouring, and oncoming traffic. One of the components of the «sense» of dimensions is the ability to estimate distances to objects.

Currently, the skill of assessing road traffic situations and predicting development is formed by drivers through self-training, as a result of practical independent activity, since training in the training center is carried out at the level of theoretical training and depends on the material base and experience of the teacher. Training in the assessment and prediction of DTS should be included in the training course «Fundamentals of Vehicle Management», which is based on the psychological mechanism of information perception.

Forecasting the development of the road situation consists in determining the likely position of vehicles, the actions of other road users, determining the trajectory of 
movement, etc. Traffic safety activities will depend on the level (speed) of the change in the forecast of non-compliance with the real development of the RTS and the value of the correct decision-making [9-11].

The purpose of this work is to improve the methods of training candidates for drivers, with the use of a training complex in the system of professional training, which has a positive impact on the safe driving of a vehicle in various road situations.

\section{Materials and methods}

Considering the conditions for the occurrence of road accidents, it can be argued that the events that occur on the road are characterized by insufficient professional skill of the driver [12].

The formation of the necessary qualities of a candidate for a driver is a rather complex process and requires a differentiated division depending on the category of training, as well as the specifics of further work figure 2 .

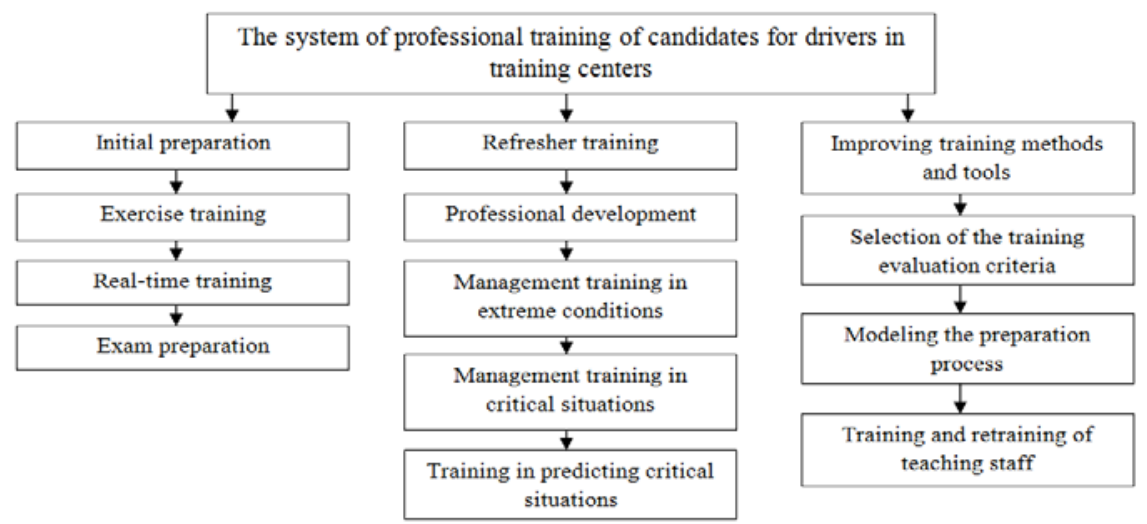

Fig. 1. Block diagram of the system of professional training of candidates for drivers in training centers

Professional training and retraining of drivers is a multi-level system, the construction of which is possible only through gradual development and improvement. Methodological support is built in such a way that the initial level of training is uniform for all categories and subcategory, retraining is carried out taking into account the initial experience and characteristics of vehicles.

Achieving the set conditions for all drivers is currently quite difficult, and it is not economically feasible. When building training methods, modern programs are based on the conditions for ensuring road safety, without taking into account the factors that affect the safety of the most vulnerable participant of the driver.

To do this, candidates for drivers must be divided into five main groups. The first group includes initial training and retraining for vehicles of category B, (B1), C, (C1). The second group carries out initial training retraining of category $\mathrm{D}$, (D1) related to the movement of buses without passengers. The third group is drivers carrying dangerous goods or carrying passengers. The fourth group carries out the transportation of "special" large-sized cargo or long-distance transportation. The fifth group is drivers working on vehicles of operational services [4].

The essence of the professional skill of safe driving involves the creation of a structure of the main elements that affect the quality of safe behavior on the road:

- the system of physiological perception when selecting information about RTS;

- Management system for receiving and processing information; 
- solving problems of creating a set of possible solutions based on oriented information processing;

- making a decision;

- ability and skill level to implement the selected solution.

These elements allow you to determine the driver's qualifications aimed at identifying dangerous road situations when driving in real time.

To achieve professional mastery of safe driving, according to A. C. Puni, it is necessary to introduce special devices, stands, and training complexes into the process of training candidates for drivers, which allow them to develop professionally important qualities necessary for the driver. In the works of E. S. Tsygankov, the use of training complexes in the training system of racing athletes helps to analyze training tracks to the smallest detail, to assess in detail the space and time for making a decision.

At the same time, the existing training methods do not provide for the use of training complexes in the preparation of candidates for drivers, but are only of a recommendatory nature, which does not allow us to form the necessary skills for safe driving in full [13-14].

The training complex allows you to use the method of mental performance of the presented exercise "mental replay of the road situation" of the main actions, including modeling actions in critical situations and repeatedly playing road situations with an analysis of the actions performed.

The analysis of labor activity shows that the performed operations are described by a number of indicators of psycho physiological qualities. The main indicator that determines the suitability of a candidate for a driver is the number of mistakes made during the execution of training actions and is determined by the expression (1):

$$
y=\frac{N-\sum_{i=0}^{a} a_{i} r_{i}}{t},
$$

where $N$ is the number of actions performed in $i$ time; $a_{i}$ - the value of the error made in penalty points; $r_{i}-$ the total number of errors; $t$ - time to complete training actions.

The mathematical model is valid for a set of training in which statistical methods can be applied. With individual training, the assessment of the readiness criterion does not allow you to evaluate professional qualities if there is no individual training trajectory.

\section{Results and Discussion}

The study conducted in [15] allowed us to establish the optimal training complex for training candidates for drivers. Further work was carried out on the basis of the training centre with the use of the automobile simulator «Fast and Furious», training of candidates for drivers of category "B" of two groups the first experimental group ( 20 people), the second control group ( 24 people) training was carried out according to the traditional training methods. The criterion of the quality indicator of professional skill reliability was determined according to the results of the practical exam.

The process of initial training took place in three stages: at the first stage, the main methods of action by the control bodies were studied, at the second stage, there is training in driving in various road traffic situations, the third stage of training in driving from the point of view of traffic safety was carried out on the analysis of critical actions (emergency situations).

According to the results of the study, candidates for drivers who were trained with the use of training complexes successfully passed the exam from the first time by $30 \%$ better in relation to the control group. 


\section{Conclusion}

In the course of observation, it was found that the training of actions in difficult critical situations is the use of automobile simulators. Simulators allow you to repeatedly simulate road situations, which will allow you to form the driving qualities necessary for safe behavior on the road, contribute to the elimination of virtual errors that are detected in candidates for drivers when driving a vehicle in simulated road conditions.

The integrated use of car simulators in the training of candidates for drivers with a smooth transition to real road conditions, allows increasing the reliability of future drivers trained in training centers.

\section{References}

1. V. Vaganov, A. Ryvkin, Driving of motor vehicles, Moscow, Transport (1991)

2. V. Mishurin, A. Romanov, N. Ignatov, The psychophysiological basis of work of drivers, Moscow, MADI (1982)

3. G. Klinkovsky, M. Afanasiev, Traffic organization, Moscow, Transport (2001)

4. A. Romanov, Trucking psychology, Moscow, Akademiya, (2002)

5. O. Mayboroda, Fundamentals of vehicle control and road safety, Moscow, Publishing center «Academy», (2007)

6. V. Kuznetsov, The problem of reliability in the training of drivers, 27 (2), pp. 233-240 (2017)

7. V. Dronseiko, Application of methods of the theory of reliability in the analysis of accidents at motor, Transport enterprises, 4, pp. 36-39 (2016)

8. M. Ronald, A. Najla, J. Beverly, L. Yingzi, Optical flow and geometric field of view in a driving simulator display, Displays, pp. 145-149 (2007)

9. A. Belyakova, B. Savelyev, Analysis of information models of simulators for training drivers of vehicles (review), Bulletin of SibADI, 16(5), pp. 558-571 (2019)

10. L. Kravchenko, Zh. Dubinina, I. Bereka, System of driver training in a driving school taking into account personal qualities, MADI, 1 (56), pp.42-48 (2019)

11. A. Calvi, A. Benedetto, M.R. De Blasiis, A driving simulator study of driver performance on deceleration lanes, Accident Analysis and Prevention, 45, pp. 195-203 (2012)

12. S. Babanov, V. Salnikov, Formation of the individual driving skills to the students of driving schools, different properties of temperament, Kazan pedagogical journal, 9, pp.76-81 (2008)

13. E. Ageev, E. Vinogradov, A. Novikov, Methodology for determining the professional qualities of motor vehicle drivers IOP Conference Series: Materials Science and Engineering, 971 (5), p. 052078 (2020)

14. E. Ageev, E. Vinogradov, Improving the system of training drivers of category " $B$ ", affecting road safety, World of transport and technological machines, 4(67), pp. 104111 (2019)

15. E. Ageev, E. Vinogradov, Principles and methods of evaluation of training complexes in the system of professional training of drivers, World of transport and technological machines, 3 (70), pp. 107-115 (2020) 